\title{
Educação musical no contexto da indústria cultural: alguns fundamentos para a formação do pedagogo
}

\begin{abstract}
Monique Andries Nogueira*
\section{Resumo}

O presente artigo tem sua origem nas reflexões advindas de pesquisa em andamento acerca das possibilidades da educação musical no contexto da indústria cultural, a partir de uma ótica que valorize seu componente emancipador, tendo como referência a conceituação adorniana de formação cultural. $O$ foco desta investigação é a atuação do pedagogo em relação à educação musical, cuja obrigatoriedade, prevista pela Lei $n$. 11769/08, tem favorecido o surgimento de diversas propostas de ensino, grande parte delas ancoradas nos produtos massificados da indústria cultural. No recorte apresentado, em primeiro lugar, apresenta-se um breve panorama da conjuntura atual, notadamente a da rede pública da cidade do Rio de Janeiro, lócus da investigação, e a demanda para o atendimento à referida lei, levando em consideração o número de licenciados em Música e a participação de pedagogos. A fim de se observar as condições de atuação/formação desse pedagogo, é apresentado, em seguida, um levantamento do espaço reservado aos conteúdos musicais nos currículos de Pedagogia das quatro principais universidades públicas do estado do Rio de Janeiro. $\mathrm{Na}$ conclusão, apontamos para elementos que possam fundar uma proposta de educação musical que seja emancipadora.
\end{abstract}

Palavras-chave: educação musical; indústria cultural; pedagogia.

\section{Musical Education in the cultural industry context: fundaments to the pedagogue formation}

\begin{abstract}
The present article was based on the reflexions which came from the research in development about the possibilities of musical education in the context of the cultural industry, considering mainly a point of view which valorizes its ability to promote emancipation, using as reference the Adorno's idea of cultural formation. This investigation is focused in the relation between the teacher and the musical education, which has been officially declared mandatory through a Brazilian law and which has allowed the development of many different pedagogical proposals; most of them based on products worldwide spread by the cultural industry. This study presents, firstly, a brief scenario of the usual context at Rio de Janeiro's
\end{abstract}

\footnotetext{
* Professora Doutora da Universidade Federal do Rio de Janeiro (UFRJ), Faculdade de Educação, Departamento de Didática. Rio de Janeiro.
} 


\section{Monique Andries Nogueira}

public schools, where this investigation takes place. It is also presented the requests to answer the needs of that brazilian law, considering the number of music teachers and the role of the pedagogues. Aiming to observe the real conditions of this pedagogue's formation/participation, this study presents the spaces destined to music subjects inside the Pegagogy Graduation Courses in the main four public universities in the state of Rio de Janeiro. In conclusion, it points some elements which can promote the development of a musical education proposal emancipating.

Keywords: musical education; cultural Industry; pedagogy.

\section{Introdução}

O presente artigo busca contribuir para a reflexão acerca da formação musical de pedagogos, trazendo dados de investigação em andamento. Iniciamos com uma breve apresentação do contexto, na qual se analisa a formação oferecida em cursos de Pedagogia, a partir da promulgação da Lei n. 11769/08, que dispõe sobre a obrigatoriedade do ensino de música. Em seguida, apresentamos alguns dados referentes aos currículos de Pedagogia de universidades públicas do Rio de Janeiro, lócus da pesquisa original. As análises foram baseadas não só nas grades curriculares, mas também em entrevistas realizadas com estudantes das referidas instituições. Por fim, apresentamos uma concepção emancipadora de formação musical, baseada no pensamento de Adorno, que se coloca como alternativa à posição evidenciada em documentos curriculares norteadores analisados, assim como na prática de professores generalistas, que privilegia um repertório ancorado nas produções massificadas da indústria cultural.

\section{Situando a problemática}

Descontentes com o reduzido espaço da música na escola básica, professores e músicos articularam um movimento que culminou com a promulgação da Lei n. 11.796/08 que incluiu um parágrafo no artigo 26 da LDB 9394/96, tornando obrigatória a presença de conteúdos da linguagem musical, mas não de forma exclusiva, no componente curricular Arte. A referida alteração estabeleceu um prazo de três anos para as escolas se adaptarem à nova exigência; entretanto, a simples aprovação detonou um movimento acerca de propostas curriculares e materiais didáticos. No bojo desse movimento, em que diferentes perspectivas de educação musical se esbarram, vemos com certa preocupação a veiculação de propostas que têm nos produtos da indústria cultural o repertório-base para o trabalho pedagógico-musical nas escolas. Em nossa opinião, há o entendimento, às vezes não revelado, de que depois de tanto tempo afastada da escola, a música precise de estratégias imediatas para conquistar seu espaço: nesse viés de reflexão, julgam que os produtos massificados, por já 
Educação musical no contexto da indústria cultural: alguns fundamentos para a formação do pedagogo

serem do conhecimento do público, seriam canais de ligação rápida do aluno com a disciplina Educação Musical. Oferecer ao estudante aquilo que ele já conhece parece ser um caminho mais fácil de aceitação. Mais uma vez, ressaltamos a atualidade do pensamento adorniano que já mostrava a capacidade da indústria cultural em construir o gosto do ouvinte, promovendo a imbricação entre o "gostar" e o "reconhecer":

Se perguntarmos a alguém se gosta de uma música de sucesso lançada no mercado, não conseguiremos furtar-nos à suspeita de que o gostar e o não gostar já não correspondem ao estado real, ainda que a pessoa interrogada se exprima em termos de gostar e não gostar. Ao invés do valor da própria coisa, o critério de julgamento é o fato de a canção de sucesso ser reconhecida de todos; gostar de um disco de sucesso é quase exatamente o mesmo que reconhecê-lo. (ADORNO, 1983, p. 165)

Buscando ocupar o espaço na escola de forma apressada, por meio de estratégias de sedução que utilizam de produtos culturais descartáveis e massificadores, o professor pode até mesmo obter um reconhecimento rápido; contudo, seu papel será, mais uma vez, semelhante ao de um animador de eventos. Sem desrespeitar o trabalho deste profissional, é preciso reconhecer que há diferenças fundamentais entre seu trabalho e o do professor.

O animador de eventos dispõe de um tempo limitado de atuação junto ao público e sua função é simplesmente a do entretenimento. Para esse objetivo pontual, é compreensível que lance mão de produtos massificados para obter êxito por meio de pronta resposta. Já o trabalho do professor é fundamentalmente diverso. O professor tem como objetivo a formação de seu aluno, isto é, contribuir para seu crescimento como ser humano pleno de potencialidades. Além disso, o tempo de convivência entre professor e aluno é muito superior e, portanto, de maior alcance. Nesse sentido, não há a urgência que justifique a utilização dos produtos massificados: é na oferta de obras musicais ricas e diferenciadas que o professor opera no sentido de ampliar os referenciais musicais de seus alunos, possibilitando experiências estéticas emancipadoras. Cabe refletir: se o professor reproduz na escola apenas o que os meios de comunicação já oferecem de forma maciça, qual é a sua função? Neste caso, a substituição do professor de música pelo $D J$ é justificada.

Como já afirmado, muito se tem produzido acerca de propostas para a chamada "volta" da música para a escola. É fundamental também refletir sobre a formação dos professores para o exercício da docência de música. Alguns defendem a participação exclusiva de licenciados em Música, em todos os níveis da escola básica, o que é obviamente inalcançável diante do número reduzido de formandos a cada ano, mesmo nas capitais e ainda em número quase insignificante no interior, diante da grande demanda. 


\section{Monique Andries Nogueira}

Um pequeno exemplo desse problema pode ser identificado na cidade do Rio de Janeiro. Sua rede pública municipal é a maior da América Latina: segundo informações presentes no sítio da própria prefeitura, são 685.279 alunos, da Educação Infantil ao Ensino Fundamental, distribuídos em 1.513 instituições (escolas, creches e espaços de desenvolvimento infantil). No entanto, na cidade do Rio de Janeiro, há apenas três cursos de licenciatura em Música, dois em universidades públicas e um em centro universitário da rede privada. A oferta de vagas no último vestibular, somando os três cursos, não alcançava nem mesmo uma centena. Levando em consideração que muitos ingressantes não chegam a concluir seus cursos, outros investem nas suas carreiras como músicos e ainda outros optam pelo trabalho exclusivo em escolas especializadas, o número de licenciados que se direciona para a escola básica é ainda mais insignificante. Diante da disparidade entre a demanda e a oferta, é fácil perceber que nem em médio prazo, caso não haja uma ampliação destas vagas, a pretensão de se contar apenas com os licenciados em Música é irrealizável.

Na nossa perspectiva, apontamos obviamente a necessidade da ampliação e fortalecimento das licenciaturas em Música. Mas entendemos ser primordial que os currículos desses cursos apresentem aos alunos a escola básica como horizonte, substituindo a histórica posição de formar preferencialmente professores para conservatórios e escolas de música, os quais esperam, depois de formados, uma atuação idealizada: classes de poucos e motivados alunos, vasto material didático, instrumentos, aparelhos de som. Não defendemos a precarização do trabalho pedagógico, mas é preciso que os futuros professores estejam preparados para lidar com a escola real, com alunos reais e que seus cursos de formação possam Ihes dar a base necessária para desenvolverem ações docentes consistentes com essa realidade. Talvez assim conseguíssemos reverter o quadro, frequente em todo o país, de fuga dos licenciados de Música da rede básica para as escolas de música (NOGUEIRA, 1994).

Alguns educadores musicais defendem a capacitação de músicos para o exercício da docência, como medida emergencial, dada a escassez de licenciados. Embora compreenda essa argumentação, entendo que esse tipo de medida já acontece em outros âmbitos como projetos sociais ligados a Organizações não governamentais (ONGs) e projetos de educação integral e já se têm produzido pesquisas que apontam justamente para a precariedade do trabalho desses profissionais, isto é, artistas sem formação pedagógica (CARVALHO, 2008). Além disso, é uma posição que segue na contramão da pesquisa em Educação, que há muito aposta justamente na profissionalização como estratégia para a valorização do professor (PIMENTA, 1999).

Levando-se em conta a tradição do sistema educacional brasileiro, o licenciado em Música atuaria do 6 ano do Ensino Fundamental ao fim do ensino médio. Resta-nos pensar no ensino de música na Educação Infantil e nos anos iniciais do Ensino Fundamental, historicamente desempenhado pelas pro- 
Educação musical no contexto da indústria cultural: alguns fundamentos para a formação do pedagogo

fessoras generalistas. Atualmente, este é um tema primordial, pois serão justamente elas as responsáveis, na maior parte do país, por implementar as modificações ditadas pela festejada lei.

Também é preciso esclarecer que a opção pelo investimento na formação do pedagogo não se dá apenas pela impossibilidade numérica do atendimento por parte do licenciado em Música. Não acreditamos que a fragmentação presente nas fases posteriores da educação deva ser antecipada. Acreditamos que o professor generalista seja o mais indicado para atuar diretamente com a criança nesta fase inicial. Obviamente há que se investir mais fortemente na sua formação artística, notadamente musical, e é nessa direção que os esforços precisam acontecer. Não estamos afirmando que a presença do licenciado em Música seja desnecessária; em muitos casos, pode vir a ser extremamente importante. Contudo, muitas vezes, essa presença é pouco significativa, tratando-se apenas de 50 minutos semanais, em atividade desconectada com o projeto educacional que está sendo vivenciado. A aula de música do especialista muitas vezes se constitui em momento artificial, de pouca reverberação no cotidiano das crianças. Seria muito mais eficaz se estes poucos licenciados em Música atuassem mais fortemente no planejamento pedagógico dos professores generalistas, inserindo propostas de conteúdos musicais, que poderiam ser implementadas por ele ou pelos professores generalistas, por períodos mais longos. É a perspectiva da parceria (BELLOCHIO, 2001) que nos parece o caminho mais produtivo e consequente. Nesse sentido, um campo de trabalho importante que se abre para o egresso de licenciatura em Música é justamente o dos cursos de formação de pedagogos.

\section{O panorama dos cursos de Pedagogia}

Passaremos a analisar a presença da Música nos currículos de formação de professores, tendo para isso a observação dos currículos de Pedagogia de quatro universidades públicas da cidade do Rio de Janeiro, a saber: Universidade Federal do Rio de Janeiro (UFRJ), Universidade Federal Fluminense (UFF), Universidade Estadual do Rio de Janeiro (UERJ) e Universidade Federal do Estado do Rio de Janeiro (Unirio).

Segundo Goodson,

a elaboração do currículo pode ser considerada um processo pelo qual se inventa a tradição. Com efeito, esta linguagem é com frequência empregada quando as "disciplinas tradicionais" ou "matérias tradicionais" são justapostas, contra alguma inovação recente sobre temas integrados ou centralizados na criança. (2008, p. 27)

Este é precisamente o caso da Música nos currículos de Pedagogia analisados. Em geral, os cursos de Pedagogia se assentam em uma lógica muito semelhante (NOGUEIRA, 2002), ainda que se percebam diferenças pon- 


\section{Monique Andries Nogueira}

tuais, quase sempre correspondentes às áreas de pesquisa mais desenvolvidas no âmbito da universidade na qual se localiza o curso. Essa lógica está baseada na consolidação de três campos distintos: o das disciplinas de fundamentos (Filosofia, Sociologia, Psicologia, História da Educação), o das metodologias (Didática, Metodologias de Ensino, Estágios supervisionados e Práticas de Ensino) e o das periféricas (que surgem a partir de demandas específicas tais como Novas Tecnologias, Educação Especial).

A Arte, entendendo-se a Música como uma de suas linguagens, apesar de ser componente curricular obrigatório da Educação Básica, deveria situarse no campo das metodologias de ensino, mas encontra-se em situação semeIhante às disciplinas do campo periférico. Quando existe, apresenta carga horária significativamente menor que outras metodologias de ensino. Além disso, sendo a Música nosso objeto de interesse nesse trabalho, é importante ressaltar que a mesma ainda é menos presente, uma vez que há uma tradição em se privilegiar a linguagem das Artes Visuais, tradição essa que tem causas históricas diversas e que não poderiam ser abordadas nos limites desse texto. Cabe apenas ressaltar que esse fenômeno - 0 do destaque dado às Artes Plásticas em detrimento das demais linguagens artísticas do campo escolar, como a Música, o Teatro e a Dança - que se verifica nas escolas de Educação Básica é repetido nas estruturas dos cursos superiores.

No currículo de Pedagogia da Universidade Federal do Rio de Janeiro (UFRJ), a disciplina Arte-Educação, de 45 horas, é oferecida no quinto período. É interessante notar, confirmando tratar-se de uma disciplina do campo periféri$\mathrm{co}$, que sua carga horária é menor do que a das demais metodologias de ensino, como Didática do Português ou Didática da Matemática. Além disso, são ofertadas disciplinas complementares de atualização dessas áreas de conhecimento, o que não acontece com a área de Arte. Na ementa da disciplina ArteEducação não há tópicos específicos da linguagem musical. Percebe-se que poderia ser operacionalizada a partir de qualquer uma das linguagens artísticas; contudo, como é maior a presença de profissionais oriundos das Artes Visuais, historicamente foi a ela que se deu ênfase inicialmente. Recentemente, foi criada a disciplina Linguagem Musical na Educação Básica, de 60 horas, mas de caráter optativo.

Na grade curricular do curso de Pedagogia da Universidade Federal Fluminense (UFF), há também a disciplina Arte-Educação, de 60 horas. Sua ementa, assim como a anteriormente analisada, está assentada nos aspectos teóricos do campo da estética, comum a todas as linguagens artísticas: aspectos históricos da educação através da arte no Brasil, o movimento das escolinhas de Arte do Brasil, conhecimento artístico como fruição, produção e reflexão, Artes Visuais, Música, Dança e o Teatro. A Música aparece nesse cenário aparentemente em condições iguais a das demais linguagens, mas uma observa- 
Educação musical no contexto da indústria cultural: alguns fundamentos para a formação do pedagogo

ção atenta revela que alguns desses tópicos, como por exemplo, o das escolinhas de Arte do Brasil, embora certamente relevante para a compreensão da história do ensino da Arte, confirma a hegemonia das Artes Visuais na ementa.

O curso de Pedagogia da Universidade Estadual do Rio de Janeiro (UERJ) prevê a disciplina Educação Estética, em cuja ementa se observa uma ênfase nos fundamentos epistemológicos e na história da educação estética no Brasil. Ainda que se reconheça uma explicitação de conteúdos mais engajados em uma perspectiva contemporânea, nota-se que não fica clara a presença da música. De acordo com dados obtidos junto a estudantes, a concretização operacional dessa ementa acontece sem nenhuma menção ao campo da Música. Isso se relaciona com o fato de esta universidade contar com cursos de graduação e pós em Artes Visuais, e não em Música.

O caso do curso de Pedagogia da Universidade Federal do Estado do Rio de Janeiro (Unirio) apresenta-se um pouco diferenciado, exatamente por esta universidade contar com prestigiados cursos de graduação e pós-graduação em Música e Artes Cênicas. Na sua grade curricular é oferecida a disciplina Arte-Educação, em cuja ementa fica clara uma justaposição de conteúdos específicos da Música e das Artes Cênicas, sem muita integração. Diante do quadro apresentado, é fácil perceber que o pedagogo, se levarmos em conta apenas o âmbito de sua formação inicial, tem poucas condições de se sentir seguro para a prática docente em música. Também assim sua trajetória, enquanto aluno da Educação Básica durante as décadas passadas, não deve the ter permitido muito contato com a linguagem musical, uma vez que esta gozava de pouco espaço no âmbito da disciplina Educação Artística. Daí a opção pelos produtos massificados, já conhecidos pelos alunos, Ihe parecer mais segura.

Nesse sentido, percebe-se a necessidade de se traçar medidas que visem o equacionamento do problema: uma vez que a importância do ensino de música esteja reconhecida e garantida por lei, é fundamental que todos os atores envolvidos na formação docente - licenciados em Música, pedagogos, pesquisadores de currículo - centrem seus esforços na busca de parcerias que viabilizem sua efetivação na escola básica, seja por meio da criação de novas disciplinas nos cursos de formação, seja por iniciativas de formação continuada.

\section{Educação musical para emancipação}

Passaremos, agora, a abordar aquilo que defendemos ser o fulcro de uma proposta de formação musical do professor generalista: educação para emancipação, a partir de um repertório de boa qualidade, intercultural e crítico.

Segundo Adorno (1996), a formação cultural (Bildung) é fenômeno que apresenta uma dupla faceta: adaptação e emancipação. Obviamente, a cultura é adaptação por se tratar de um campo pelo qual o indivíduo se conecta com 


\section{Monique Andries Nogueira}

seu grupo social. É, muitas vezes, a partir de tradições culturais que se vivencia o sentimento de pertencimento a este grupo: desde as canções de ninar, passando pelas tradições folclóricas e costumes populares, chegando às manifestações mais contemporâneas, vão se construindo no indivíduo as características que o tornam parte daquela comunidade. Isto é, não somos brasileiros apenas por termos nascido no Brasil, mas somos brasileiros porque estamos imersos no caldo cultural brasileiro, o que nos faz entrar em sintonia, pelo menos em grande parte, com as manifestações e percepções do nosso povo. Nesse sentido, a faceta da adaptação foi necessária para que o homem se organizasse em grupos, o que propiciou sua sobrevivência, o que não teria acontecido caso permanecesse como indivíduo isolado.

Mas a cultura também é emancipação, é possibilidade de se ir além do que está posto, preestabelecido. Por meio da cultura, podemos alargar nossos horizontes, conhecer outras realidades, outras visões de mundo, nos constituir de forma única e original. Podemos, principalmente, ampliar nossos referenciais estéticos, permitindo uma fruição rigorosa e fundante de outras lógicas possíveis.

O mesmo tipo de raciocínio se pode estender à educação, notadamente na sua modalidade escolar, pensada a partir desses dois polos. A educação é adaptação, obviamente, porque por meio dela nos inserimos no mundo letrado, passando a fazer parte de uma comunidade. Tradicionalmente, os currículos escolares são estabelecidos a partir desta lógica, oferecendo ao estudante os instrumentos para sua inserção social. Mas a educação também pode e deve ser emancipação, ao proporcionar ao estudante os meios para alargar seus referenciais, alçar voo, ir além da mesmice. Adorno revela essa preocupação ao apresentar seu conceito de educação:

[...] Assumindo o risco, gostaria de apresentar minha concepção inicial de educação. Evidentemente não a assim chamada modelagem de pessoas a partir do seu exterior; mas também não a mera transmissão de conhecimentos, cuja característica de coisa morta já foi mais que destacada, mas a produção de uma consciência verdadeira. (1995a, p. 141)

No entanto, a produção de consciência não é tarefa fácil, principalmente levando-se em conta o contexto no qual a educação se dá. Vivemos em um mundo administrado, regido por falsas promessas de realização material, que pouco espaço oferece para uma vida plena e autônoma.

Adorno já alertava para esse problema: "a organização do mundo converteu-se a si mesmo imediatamente em sua própria ideologia. Ela exerce uma pressão tão imensa sobre as pessoas, que supera toda a educação" (1995a, p. 143). Nesse sentido, fica fácil entender porque tantas propostas de educação 
Educação musical no contexto da indústria cultural: alguns fundamentos para a formação do pedagogo

musical optam pelo que já está estabelecido, pelos produtos forjados pela indústria cultural, pelos sucessos fabricados.

Para o pedagogo em formação, essa conceituação assume importância avassaladora. Centrar sua formação musical no polo da adaptação é reduzir a educação musical a mero enfeite na grade escolar: é repetir as mesmas atitudes reducionistas que marcaram a presença da música na escola brasileira. Em geral, tanto nos cursos de magistério em nível médio, quando nos poucos cursos de Pedagogia que oferecem disciplinas ligadas à música, o que se espera do professor formador é que ele ensine um repertório adaptável ao calendário cívico ou alguma atividade que possa ser utilizada no cotidiano das escolas. $\mathrm{E}$ isso no curto espaço de uma disciplina, quase sempre com carga horária diminuída em comparação com as demais áreas de conhecimento (NOGUEIRA, 2010).

Defendemos, ao contrário, que o professor formador, no âmbito dos cursos de Pedagogia, possa propor uma outra lógica: a de se pensar a música como área de conhecimento humano, como linguagem que pode ser aprendida e ensinada, para além dos estereótipos do talento. A esse respeito, Adorno, ao se pronunciar pela demolição do fetiche do talento, revela:

[...] o talento não é uma disposição natural, embora eventualmente tenhamos que conceder a existência de um resíduo natural - (...), mas que o talento, tal com verificamos na relação com a linguagem, na capacidade de se expressar, em todas as coisas assim, constitui-se, em uma importantíssima proporção, em função de condições sociais... (1995b, p. 172)

Algumas vezes, o trabalho com o licenciando em Pedagogia é negligenciado justamente por essa inadequada concepção de talento: ora, dizem, os talentosos para a música estão nos cursos de bacharelado em música; portanto, para pedagogos, que não têm formação específica, que não tocam nenhum instrumento musical, apenas uma relação de técnicas aligeiradas deve ser suficiente. É exatamente o oposto disso que defendemos no espaço desse artigo. $O$ trabalho musical a ser desenvolvido na formação dos pedagogos, futuros professores responsáveis pelo ensino de música na Educação Infantil e anos iniciais do Ensino Fundamental, deve ser de tal forma vigoroso que possibilite a eles construírem as bases de uma prática docente musical consistente e emancipadora. Obviamente, o espaço reduzido nas grades curriculares destes cursos é um problema, mas não pode ser justificativa para a não realização do trabalho. Talvez seja justamente realizando um trabalho de boa qualidade que poderão os profissionais formadores, exigir, com o apoio de seus formandos, a ampliação desse espaço. 


\section{Monique Andries Nogueira}

Talvez por isso também se invoquem, como já foi dito, os recursos de produtos da indústria cultural para facilitar o trabalho com os alunos. Para obter uma resposta rápida, objetivando o resultado final e não o desenvolvimento do processo criador, o pedagogo lança mão desses produtos no seu planejamento. Novamente, o ideário de uma educação para a adaptação é preponderante, em detrimento de uma proposta emancipadora. Uma educação musical emancipadora seria marcada pela opção por obras musicais de reconhecido valor estético, populares ou eruditas, de gêneros e estilos variados, oriundas de diferentes segmentos sociais, com certeza não de rápida assimilação, mas certamente possibilitadoras de uma fruição aprofundada e prenhe de novas leituras de mundo.

Tal afirmação possibilita, certamente, questionamentos acerca de como definir o que viria a ser uma obra musical de valor estético. Não poderíamos aqui, no limite de um artigo, empreender uma argumentação vigorosa a esse respeito. No entanto, penso que o que marca diferencialmente uma proposta de cunho adorniano, isto é, a não submissão aos interesses comerciais, em detrimento dos interesses estéticos, é justamente a crença na possibilidade do julgamento. Para Adorno, um bom ouvinte é aquele que "escuta além do detaIhe; estabelece inter-relações de maneira espontânea e tece juízos bem fundamentados, que não se fiam em meras categorias de prestígio ou no arbítrio do gosto" (ADORNO, 2011, p. 61). Atualmente, a capacidade de julgar parece estar em baixa: sob o argumento de que todo julgamento é arbitrário, defendem-se, muitas vezes, o relativismo total, ou ainda a igualdade entre todas as manifestações artísticas. Mesmo reconhecendo que defendemos uma posição minoritária, insistimos que a partir de uma série de critérios estéticos, referentes ao específico da linguagem musical tais como o domínio da técnica composicional, a temática, construção melódica e harmônica, diversidade rítmica, originalidade, criatividade, entre outros, seja possível avaliar se um conjunto de composições musicais se mostra relevante para o trabalho pedagógico musical. Da mesma forma, isso acontece com outras áreas de conhecimento na escola: os professores, constantemente, elegem algumas obras como prioritárias para seu trabalho docente. Mesmo levando em consideração a necessidade de se problematizar o conceito de clássico ou universal, a fim de se incluir obras de âmbito local e particular, cremos que o mesmo pode ser feito em relação à música.

\section{Conclusão}

A partir do que foi exposto, poder-se-ia perguntar como se daria, enfim, uma formação de estudantes de Pedagogia no tocante à linguagem musical. Este talvez seja um dos grandes desafios colocados aos formadores: que conteúdos ensinar ao futuro pedagogo para que ele possa construir sua própria prática docente em música? Não temos a pretensão de organizar aqui um rol de conteúdos ideais para todos os cursos de Pedagogia, até porque esta mesma 
Educação musical no contexto da indústria cultural: alguns fundamentos para a formação do pedagogo

relação não seria coerente com a diversidade de um país continental como o Brasil. No entanto, afirmamos ser possível o estabelecimento de princípios que poderiam nortear toda e qualquer proposta curricular: tais princípios, ao contrário do que historicamente têm sido concebidos, estariam apoiados em uma concepção de educação emancipadora.

O que pretendemos defender, como conclusão de um artigo que assume sua incompletude por se tratar de um recorte de investigação em andamento, é que sejam estabelecidas outras bases para a formação musical dos pedagogos. Que sejam estas bases forjadas no projeto de emancipação humano por meio das obras musicais de boa qualidade musical-educativa, a fim de que os professores possam despertar em seus alunos um crescimento estético real, um alargar de conceitos, uma apropriação de mais uma forma de expressão, para além da escrita. Receio que, se contrariamente a isso se consolidar a opção exclusiva pelos produtos massificados da indústria cultural, mais uma vez teremos frustrada a esperança de um projeto real de educação musical: estaremos apenas formando consumidores musicais dóceis, pouco críticos e adequados ao statu quo.

\section{Referências}

ADORNO, T. W. O fetichismo na música e a regressão da audição. Coleção Os Pensadores. 2. ed. São Paulo: Abril Cultural, 1983.

Educação - para quê? Educação e emancipação. 2. ed. Rio de Janeiro: Paz e Terra, 1995a.

Educação e emancipação. Educação e emancipação. 2. ed. Rio de Janeiro: Paz e Terra, 1995b.

. Teoria da Semicultura. Educação e Sociedade. Revista Quadrimestral de Ciência da Educação, ano XVII, no. 56. Campinas: Papirus, 1996.

. Tipos de comportamento musical. Introdução à Sociologia da Música. São Paulo: Unesp, 2011.

BRASIL. Lei n. 9394/96 de Diretrizes e Bases da Educação Nacional, 1996.

BELLOCHIO, Cláudia R. Educação musical: olhando e construindo na formação e ação de professores. Revista da ABEM, n. 6, setembro de 2001.

CARVALHO, Lívia M. O ensino de artes em ONGs. São Paulo: Cortez, 2008.

EDUCAÇÃO em números. Disponível em: Erro! A referência de hiperlink não é válida. em 15 de maio de 2011.

FONTERRADA, Marisa Trench de O. De tramas e fios - um ensaio sobre música e educação. 2. ed. São Paulo: UNESP, 2008.

GOODSON, Ivor F. Currículo: teoria e história. 8. Ed. Petrópolis: Vozes, 2008. 


\section{Monique Andries Nogueira}

NOGUEIRA, Monique Andries. A formação do ouvinte: um direito do cidadão (propostas para a educação musical no ensino fundamental). Dissertação de mestrado. Faculdade de Educação da UFG. Goiânia, 1994.

A formação cultural de professores ou a arte da fuga. Tese de doutorado. Faculdade de Educação da USP, 2002.

A música nos currículos de Pedagogia: espaço em disputa. Anais do XIX Congresso Anual da Associação Brasileira de Educação Musical. Goiânia, 2010.

PIMENTA, Selma Garrido. Formação de professores: identidade e saberes docentes. In: PIMENTA, S. G. (Org.). Saberes pedagógicos e atividade docente. São Paulo: Cortez, 1999.

\section{Correspondência}

Monique Andries Nogueira - Universidade Federal do Rio de Janeiro, Faculdade de Educação. Av. Pasteur, 250, fundos - Praia Vermelha, Urca. CEP 22290-240 - Rio de Janeiro.

E-mail: andries@terra.com.br

Recebido em 05 de janeiro de 2012

Aprovado em 06 de julho de 2012 